\title{
Cash limits squeeze in London AHA(T)s
}

This year's financial problems in the NHS have been caused not by any direct cut in the Health Service budget but by the Government's insistence that authorities should live within their cash limits and its refusal to increase these limits to cope with rising costs.

Patrick Jenkin admitted fairly early on that the cash limits squeeze-which he then put at about $£ 90-£ 100 \mathrm{~m}$ throughout the NHS but which is now estimated to be $f 121 \mathrm{~m}$ - would affect some clinical services. At best, authorities who have been benefiting from RAWP have had to defer much-needed developments. But the London teaching authorities are the losing areas of losing regions, and the squeeze has. meant substantial cuts to their budgets and some dramatic proposals to limit services, with clinics, wards, and hospitals being closed-often permanently. London CHCs estimate a.loss of nearly 3000 beds by March 1980. We look here at what the squeeze has meant to the London teaching areas. Later we hope to do the same for some areas outside London.

\section{On top of overspending}

The cash limits for 1979-80 allowed for pay rises of $5 \%$ and were based on an estimate that inflation would be $8.5 \%$ higher in the fourth quarter of 1979 than in the same quarter in 1978. Since then inflation has risen sharply (to about $17.5 \%$ ) and VAT, which the NHS cannot recoup, has almost doubled.

Pay rises to Health Service workers, which have been much greater than $5 \%$, have been largely funded, though authorities knew from the beginning that they would have to find $£ 23.4 \mathrm{~m}$ themselves. Since then smaller sums have been added: in September $\mathrm{Mr}$ Jenkin warned that authorities would have to find $£ 3.4 \mathrm{~m}$ of the cost of the Clegg avrard for ambulancemen and ancillary staff, and the recent improvements in consultants' contracts, estimated at about $f 3 \mathrm{~m}$ in a full year, will come out of cash limits.

In several London districts the squeeze has come on top of overspendings, and inevitably these are the districts where proposals for savings seem the severest. In Lambeth, Southwark, and Lewisham the commissioners have to claw back about $f 5.5 \mathrm{~m}$ by next March (and then repay a further $f 4.3 \mathrm{~m}$ that the area owes from past overspendings). But Lambeth, Southwark, and Lewisham is not unique in its overspending. In Camden and Islington the Islington district has a cumulative overspending of about $£ 1.4 \mathrm{~m}$; Wandsworth and East Merton district overspent by almost $£ \frac{1}{2} \mathrm{~m}$ last year, as did the North-west district of Kensington and Chelsea and Westminster and the North Hammersmith district of Ealing, Hammersmith, and Hounslow. In Ealing also, the area is currently overspending by about $£ \frac{1}{2} \mathrm{~m}$ on running the new Ealing Hospital, which remains only partly open because of lack of money.
Because health authority treasurers have assumed that the squeeze would be a one-of event, with this year's inflation being fully funded in next year's allocation, they have looked mainly for temporary ways of saving money; but in the overspent districts some of the savings need to be recurring. Ealing, Hammersmith, and Hounslow's treasurer, for example, estimates that his area needs to make savings in recurrent expenditure of about $£ 1 \mathrm{~m}$ to reduce the rate of expenditure and non-recurring savings of about $£ 3 \mathrm{~m}$ to eliminate the overspending this year.

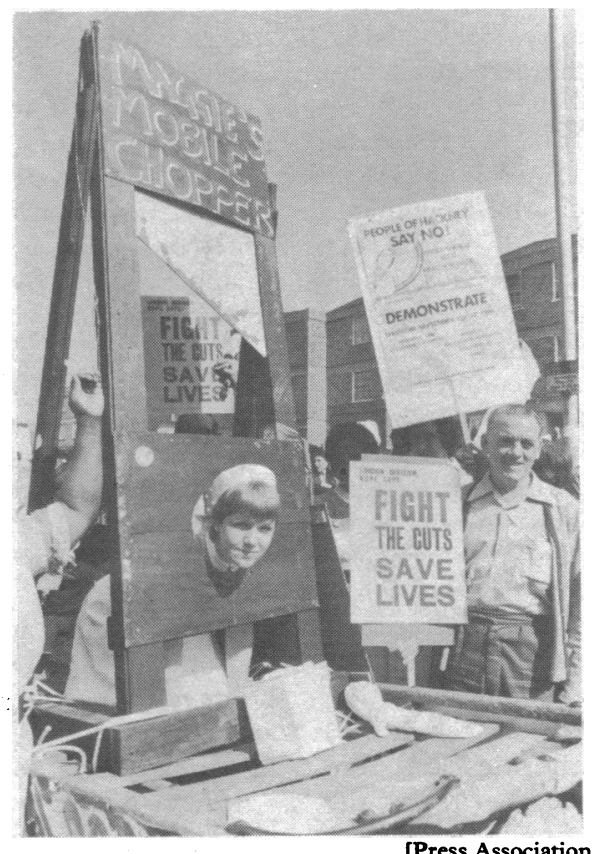

Health Service unions have pledged their opposition to the cuts, though several closures have already taken place without active resistance.

The first London area to respond to the squeeze by making some hard decisions on savings-Kensington and Chelsea and Westminster, which accepted a package of cuts in July-decided that balancing its budget properly by March 1980 would demand measures that were too draconian. It therefore quietly decided to aim to be in true balance by March 1981, though it could meet its cash limit in March 1980 by adjusting its cash balances. The area treasurer told the authority in October that because of the economy measures in hand the AHA(T) would meet its cash limit in March, though in income and expenditure terms it would be overspent by about $£ \frac{3}{4} \mathrm{~m}$. Some other AHA(T)s have taken a similar approach, though most did not decide on their major savings until the second half of this financial year.
Even with this extra breathing space the reductions still have to be made and all authorities are taking action that will affect patients to some extent. The much-quoted waste in administration has yielded few savings. Administrative costs have already been reduced following a Labour Government instruction, and much ordinary administration and planning is being neglected while administrators spend their time drawing up schemes for cutting services and trying to get agreement on how to do it. Indeed, many administrators argue that the Service needs more management rather than less if wasteful practices are to be eliminated and budgets kept under control.

\section{Staff}

Since they consume about $70 \%$ of the NHS budget, an obvious but sensitive area to tackle is staff costs. Most areas have reaffirmed existing "no compulsory redundancy" policies, though City and East London AHA(T) has warned that it may have to resort to redundancy after natural wastage and redeployment have been exhausted. Although some groups of staff have very high turnover rates, the turnover is often confined to relatively few posts, which limits the ability to shed staff by natural wastage. In nursing and secretarial posts not enough NHS staff can be recruited, and $\mathrm{AHA}(\mathrm{T}) \mathrm{s}^{\prime}$ decisions to limit spending on (more expensive) agency staff means that the service to patients will be affected. Though nurses especially can be moved from closed wards to take over jobs held by agency nurses, some might leave rather than transfer to the traditionally unpopular jobs that agency staff fill.

In other jobs, predominantly the ancillary grades, overmanning and excessive overtime are widely admitted. Many districts, prompted by their RAWP cuts, have already begun the slow process of removing these uneconomic practices, but the need to tackle the problem fast has in some cases meant the loss of hard-won co-operation from the trade unions.

Doctors are not exempt from the cuts either. Ward closures mean that fewer housemen will be needed and must also affect postgraduate specialist training programmes. Some closures will force consultants to move or reduce their sessions simply because they will have few patients to see. North-east Thames RHA has already frozen new consultant appointments and will authorise replacements only to prevent a service from breaking down. Control of overtime payments includes junior hospital doctors' UMTs, and juniors will also be affected by the plans of the Thames regions to limit the use of agency medical staff. Kensington and Chelsea and Westminster $\mathrm{AHA}(\mathrm{T})$ stopped using agency doctors in September, South-west Thames RHA told its areas to try not to use them from 1 November, and the other three regions hope to follow suit.

Though little has been said publicly about the effects on medical education, many medical academics are worried that the effects of the cost-saving measures, particularly ward closures, will seriously undermine $\operatorname{AHA}(\mathrm{T}) \mathrm{s}^{\prime}$ ability to provide facilities for teaching and research.

\section{Capital and counterproductive measures}

Improvements, maintenance, and minor capital schemes are among the first items to 


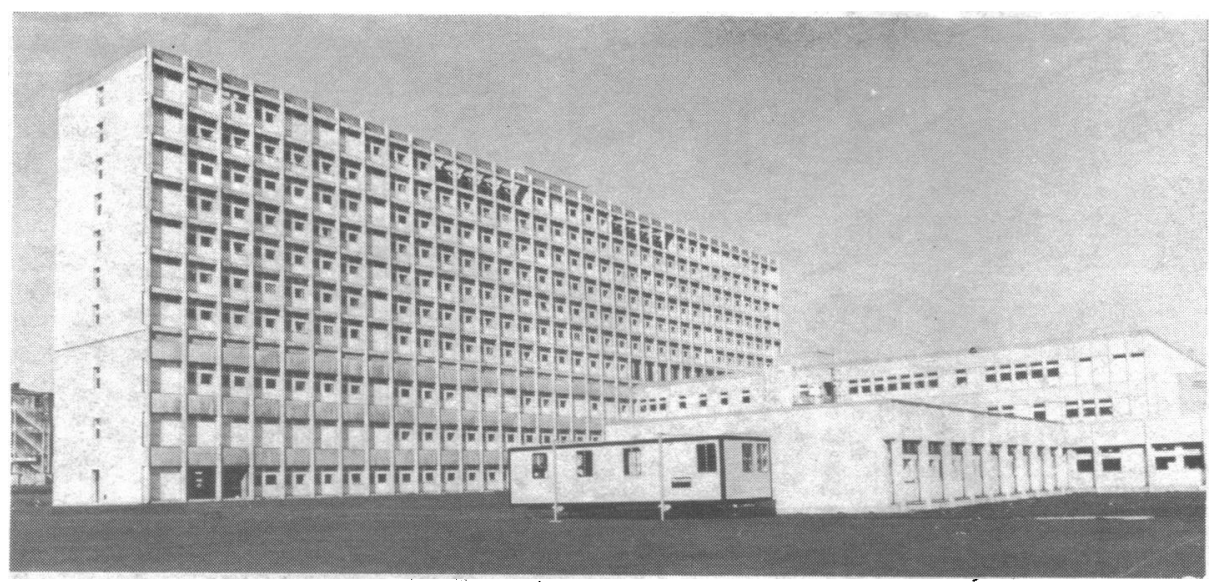

The new Ealing Hospital remains only partly opened because of lack of revenue

go when savings have to be made, and this year has been no exception, despite the reluctance of districts to put off much-needed repairs and improvements. With London's legacy of old buildings, these are false economies that will only build up more expensive problems in the future.

North-east Thames RHA has reversed its policy of converting spare revenue to capital, and by deferring schemes it has taken money out of this year's capital budget to ease its revenue position at the year end; it has also encouraged its areas to do the same. But, as the finance group of Camden and Islington AHA(T) pointed out, the NHS is if anything shorter of capital than it is of revenue. Both North-east Thames and South-east Thames, which has made just under $£ 2 \mathrm{~m}$ available to its areas by the same mechanism, need to pay this money back into their capital budgets eventually, so these sums will have to be found through genuine savings next year

Another counterproductive measure that most districts have adopted is limiting outpatient prescribing. Overall the NHS pays more if patients take drugs prescribed by a GP, but the cost does not then come from hard-pressed health authority budgets.

Other savings have more hidden costs in terms of the burdens they throw on to other welfare services. Closures of psychiatric units, for example, may well create extra costs for agencies as diverse as social services and the prisons.

\section{Closures}

The cuts that have raised the most vocal opposition are closures. As authorities have tried to some extent to protect their nascent community and priority services, so the bulk of the closures are falling on acute wards Again, the most efficient districts, with the highest bed occupancies and throughputs, are the hardest hit. Districts with lower occupancies argue that they can maintain their existing level of service if they can increase their efficiency.

One problem that his been highlighted in Lambeth, Southwark, and Lewisham is the effects on regional and supraregional specialties. The work loads of these high-cost specialties have tended to outpace those of ordinary acute specialties and so have taken more than their fair share of the budget. In King's district, for example, the work load of the district specialties has actually fallen over recent years, while that of the superspecialties has
[North-west Thames RHA

gone on rising. In the AHA(T)s of North-east Thames, where regional specialties are funded at their activity levels in 1976-7, increases in their work loads have meant less money for district services.

In these inner city areas of London authority members have been faced with the choice of maintaining district services (and trying to shift the balance towards community services, the elderly, and the handicapped) or maintaining regional and national specialties that are not easily provided elsewhere. In the face of such unpalatable decisions votes have been close and most authorities have settled for cuts to both types of services.

This dilemma prompted the members of Lambeth, Southwark, and Lewisham AHA(T) to refuse to make extra economies to meet this year's squeeze. Having decided to preserve district services, members were faced with a breakdown from their DMTs of the effects (in terms of numbers of patients not

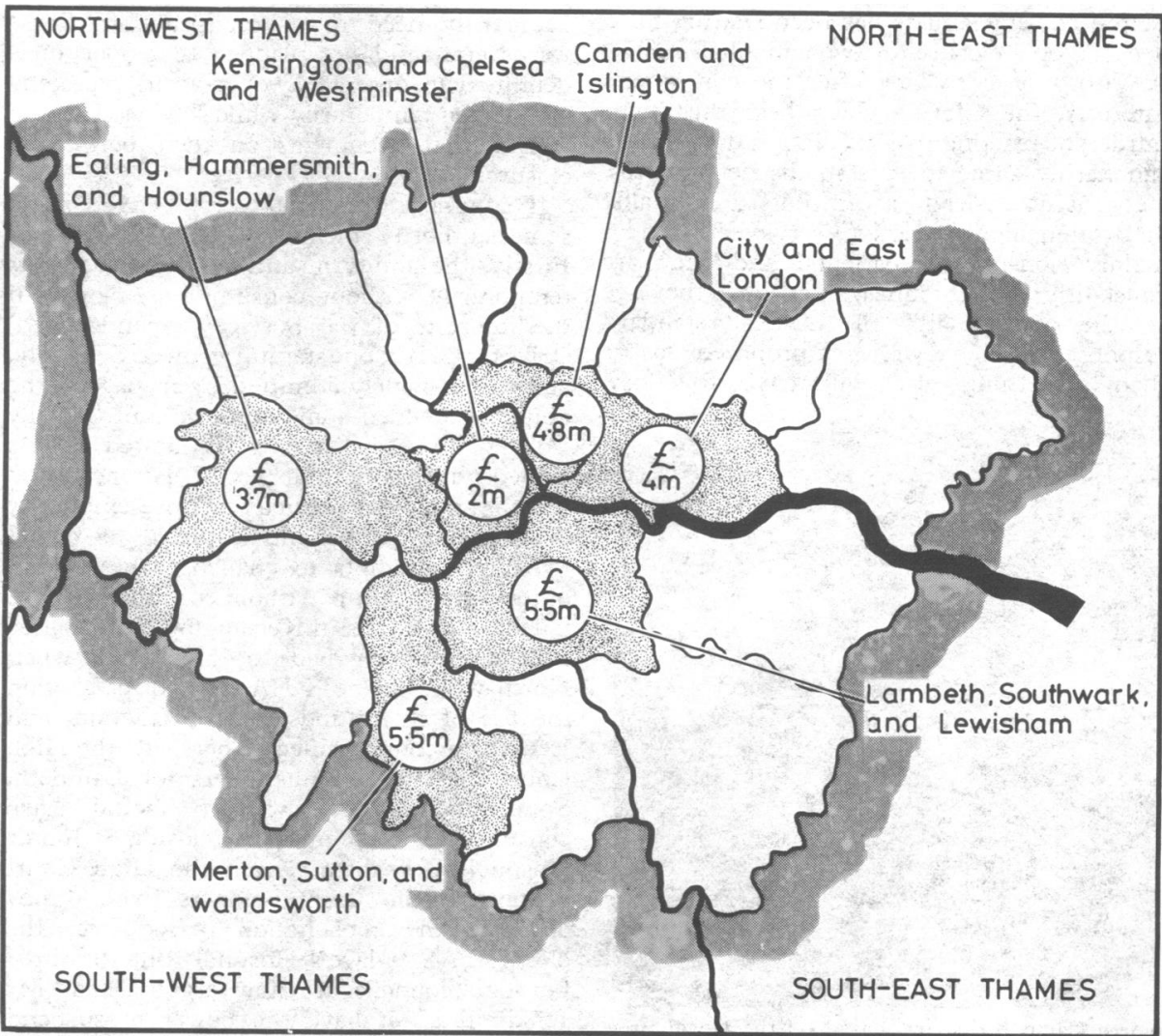

Amounts that London's AHA(T)s need to save this year.

treated) of cutting the high-cost specialties, and they refused to make the extra savings. Ealing, Hammersmith, and Hounslow AHA(T) faced a similar problem and has resolved it by fudging the issue. After accepting a package of cuts that it considered would not affect services to area residents or diminish the facilities for teaching and research, the $\mathrm{AHA}(\mathrm{T})$ has refused to make any further cuts until regional RAWP is sorted out. Nevertheless, it has also accepted the need to stay within cash limits and to take any urgent measures that may be needed if the forecast savings are not achieved in 1980-1. The authority has decided to try to pay off any non-recurring debt not met by the savings already agreed with money raised from selling unwanted sites.

\section{Haste}

The major difficulty of this year's squeeze and the reason why often fairly small reductions in overall budgets are having such a disproportionate effect on services is the sheer haste with which savings are having to be made. Merton, Sutton, and Wandsworth AHA(T) first decided to make economies by March 1981. In October, after discussions with its region, it decided it would have to make them by March 1980. The change has meant a much harsher package of closures. These include the transfer of services from St George's Hospital, Hyde Park, to Tooting before building is finished, with the danger of "losing" part of the specialties of cardiology and cardiothoracic surgery because their permanent accommodation will not be ready until 1981.

All the London teaching areas were already facing reductions through RAWP over the next few years and several had well-developed plans to rationalise their services to live within 
their reduced budgets in the 1980 s and beyond (and at the same time to expand their priority services). The present squeeze has totally upset operational planning: rationalisations are having to be brought forward hastily, the developments deferred, and the savings used to run the existing service. In Newham district, for example, savings that were to have been used to build up CSSD and pathology facilities for the new nucleus hospital have been diverted for general use; and in North Camden a psychogeriatric development has been delayed and the reserves used to meet this year's shortfall.

The London community health councils are worried about the overall effect that the piecemeal decisions made by individual authorities will have on the health services of London. As well as individually resisting the closures in their own districts, a group of CHCs have got together to catalogue the closures in the capital. They estimate that almost 3000 beds will have closed by March 1980 and that nine casualty departments will be limiting their services. Like the CHCs, many GPs are worried about the effects of closed accident and emergency departments and hospital beds and the load that will fall on community services, and they are starting to voice their concerns through family practitioner and local medical committees.

\section{Consultation}

Though most authorities have made their hard decisions and left their DMTs to implement them, the decision-making does not end there. This winter and spring will see a string of formal consultation documents on permanent closures (one district has to produce seven). Consultation takes at least three months and usually longer, especially if the proposals have to go to the Secretary of State (Tower Hamlets has been waiting for a decision on a closure for two and a half years).

With a brief to look after the consumer's interests, the CHCs, which bear the major burden of reacting to consultation documents, can hardly agree to cuts in district services. Yet it is no easier to accept cuts to specialist (and often highly emotive) services that treat mainly non-district patients, and they are constantly brought up against what they see as the "blackmail" of DMTs' standard response: that if they reject a proposed closure then something else will have to close,

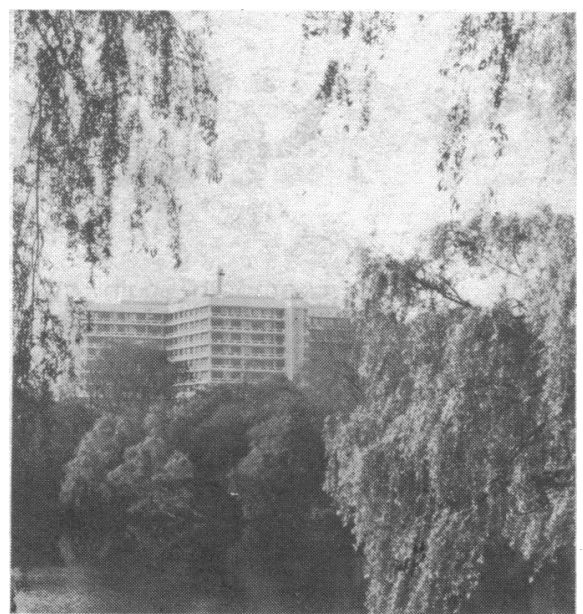

North Camden district, based on the Royal Free, has had to use reserves planned for priority services just to keep existing services going.

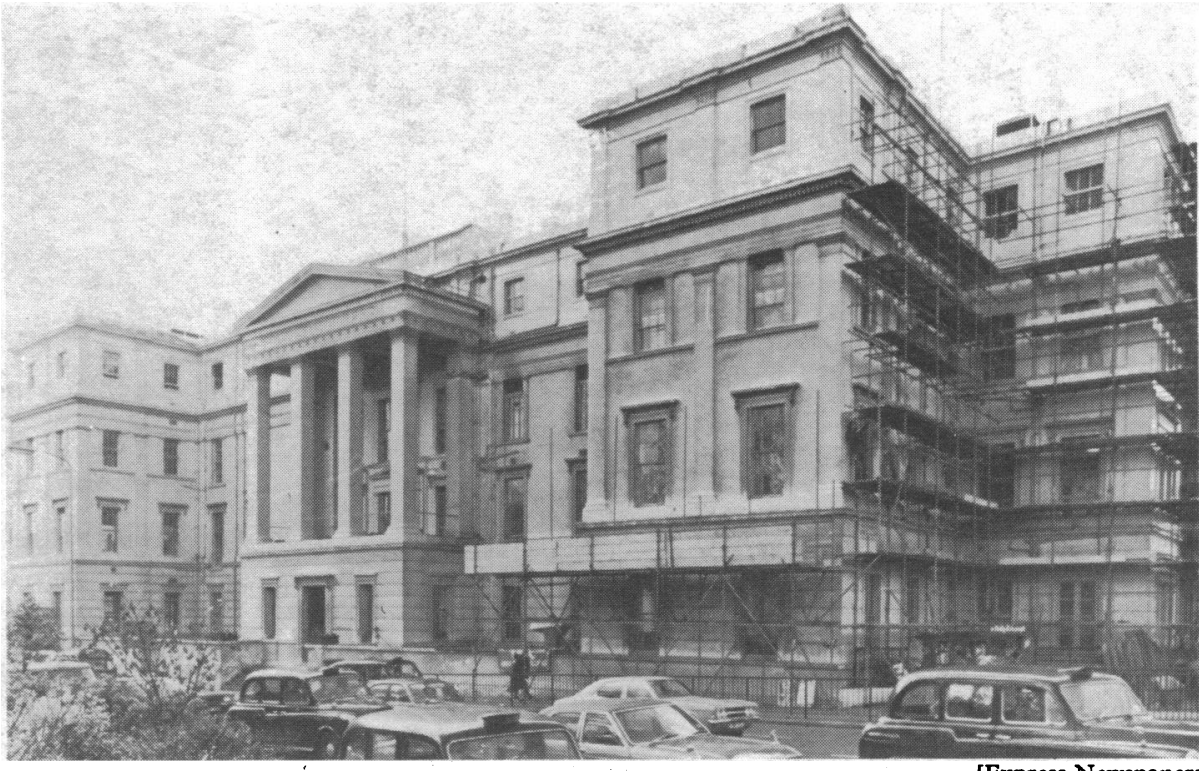

[Express Newspapers

The old St George's Hospital at Hyde Park Corner is to be closed earlier than planned because Merton, Sutton, and Wandsworth AHA(T) cannot afford to run both it and the new hospital at Tooting.

probably with more damaging consequences.

The CHCs' ability to come up with alternative proposals, which the procedure demands if they reject an area's plan, will be sorely tried, and many decisions are likely to end up on the Secretary of State's desk as CHCs and areas fail to agree. At best this can only discredit the consultation process and, at worst, areas could be put into an impossible position if the Secretary of State backs the community's desire for "much-loved smaller units" (many closure plans concern such units) and rejects areas' plans.

A bitter battle has already been played out over temporary closures, which authorities are using to make quick savings, since they do not necessarily need formal consultation. Some wards and units are planned to reopen on a definite date, others may open again, but many are closing temporarily while DMTs draw up consultation documents on their permanen closure.

Temporary closures worry CHCs (and some authority members) for two reasons. Firstly, the ability of an AHA to close units temporarily without consultation (allowed if the interests of the Service demand speed) strikes at CHCs' one statutory power. Secondly, and this is widely admitted by managers, the ability to reopen some sorts of unit, usually isolated or specialist ones, is limited after skilled staff has been dispersed elsewhere, and temporary closure in such cases pre-empts any decision on a permanent closure.

Several attempts to challenge the legality of temporary closure without consultation have failed. Two CHCs in Kensington and Chelsea and Westminster had to draw back when North-west Thames RHA refused to sanction the use of their funds for court action, and Lewisham council failed to persuade the High Court that the commissioners for Lambeth, Southwark, and Lewisham should have consulted before temporarily closing St John's Hospital, Lewisham. Again the High Court supported the commissioners when they curtailed the consultation period over the closure of St Olave's Hospital. But the three borough councils are now arguing that $\mathrm{Mr}$ Jenkin did not have the power to suspend Lambeth, Southwark, and Lewisham AHA(T) and appoint commissioners.

\section{Next year}

Authorities' ability to save the sums they have to-and to minimise the effects on patient care-clearly depend on the cooperation of NHS staff. Though the unions have opposed the cuts vigorously and threatened industrial action, DMTs might find it as hard to gain the co-operation of consultants. As a consultant member of Lambeth, Lewisham, and Southwark AHA(T) said before it was suspended, the only way his DMT could prevent his seeing patients was to close down his clinics and beds. In many cases consensus within DMTs has been severely strained, and because of the speed with which they have had to be drawn up many of the measures that $\operatorname{AHA}(T) s$ have sanctioned have been imperfectly thought out. As the proposals and their implications are worked out more fully, they may be slowed down or modified and may yield fewer savings. More important, no one knows quite what the effects on patients will be. The difficulty in health service budgeting, which bedevils the arguments about the effects of cuts, is the problem of assessing outcomes in the NHS: what reductions (or increases) in specific budgets mean in terms of patients treated and the quality of their care. AHA members need to know the answers to these questions, and at least one London AHA(T) has set about trying to find ways of answering them.

Next year RAWP may not be such a problem for London areas. North-west Thames RHA has suspended regional RAWP for a year to ease the problems of its $\operatorname{AHA}(T) s$, and $\mathrm{Mr}$ Jenkin has hinted that he will slow down on national RAWP. Nevertheless, next year's development money is only about $\frac{1}{2} \%$, and at least twice this amount is needed to keep up with developments in treatment and demographic change. Cash limits will again be crucial. Ministers have already warned that NHS workers' pay rises will have to be traded off against services to patients, which suggests that next year's limits may be squeezed as tight as this year's. In such a climate the pressure to find out the real effects of financial cuts on patients will become greater and the need to know more important. 